\title{
Childhood Obesity Declines Project: An Exploratory Study of Strategies Identified in Communities Reporting Declines
}

\author{
Phyllis G. Ottley, PhD, ,* Nicola Dawkins-Lyn, PhD, MPH, Carole Harris, PhD, \\ Carrie Dooyema, MSN, MPH, RN, Jan Jernigan, PhD, Tina Kauh, PhD, \\ Laura Kettel Khan, $\mathrm{PhD}^{3}$, and Deborah Young-Hyman, $\mathrm{PhD}^{5}$
}

\section{Abstract}

Background: Although childhood obesity rates have been high in the last few decades, recent national reports indicate a stabilization of rates among some subpopulations of children. This study examines the implementation of initiatives, policies, and programs (referred to as strategies) in four communities that experienced declines in childhood obesity between 2003 and 2012.

Methods and Results: The Childhood Obesity Decline project verified obesity declines and identified strategies that may have influenced and supported the decline in obesity. The project used an adaptation of the Systematic Screening and Assessment method to identify key informants in each site. Four settings were highlighted related to childhood: (1) communities, (2) schools, (3) early care and education, and (4) healthcare. The findings indicate that programs and policies were implemented across local settings (primarily in schools and early childhood settings) and at the state level, during a timeframe of supportive federal policies and initiatives.

Conclusions: Multilevel approaches were aimed to improve the nutrition and physical activity environments where children spend most of their time. We hypothesized that other, more distal strategies amplified and reinforced the impact of the efforts that more directly targeted children. The simultaneous public health messaging and multilayered initiatives, supported by cross-sector partnerships and active, high-level champions, were identified as likely important contributors to success in attaining declines in rates of childhood obesity.

Keywords: community interventions; evaluation; policy

\section{Background}

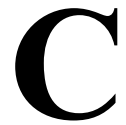

hildhood obesity rates in the United States have been high over the past two decades, with $\sim 19 \%$ of sity 1,2 Hildren ages $2-19$ years considered to have obe. obesity rates have begun to stabilize among some subpopulations of children. ${ }^{3}$ These stabilizations suggest recent progress in impacting the childhood obesity epidemic. ${ }^{4}$ Numerous federal, state, and local programs and policies designed to reduce obesity have been implemented across the United States. However, little is known about the types or combinations of programs and policies that may be influencing obesity in children. ${ }^{5}$ This study examines the initiatives, policies, programs, and practices (hereafter called strategies) implemented in four municipalities that experienced declines in childhood obesity over the last decade.

\section{Framework for Addressing Childhood Obesity}

Significant federal, state, and local investments have been made to address childhood obesity. Research suggests that effective approaches to reducing childhood obesity may be multilevel. ${ }^{6}$ Multilevel approaches aim to improve the nutrition and physical activity environments where

\footnotetext{
'Division of Violence Prevention, Centers for Disease Control and Prevention, Atlanta, GA.

${ }^{2}$ Division of Health, Research, Informatics, and Technology, ICF, Atlanta, GA.

${ }^{3}$ Division of Nutrition, Physical Activity, and Obesity, Centers for Disease Control and Prevention, Atlanta, GA.

${ }^{4}$ Research-Evaluation-Learning Unit, Robert Wood Johnson Foundation, Princeton, NJ.

${ }^{5}$ Office of Behavioral and Social Science, National Institutes of Health, Bethesda, MD.

*Dr. Phyllis Ottley was at ICF at the time of the study.
} 


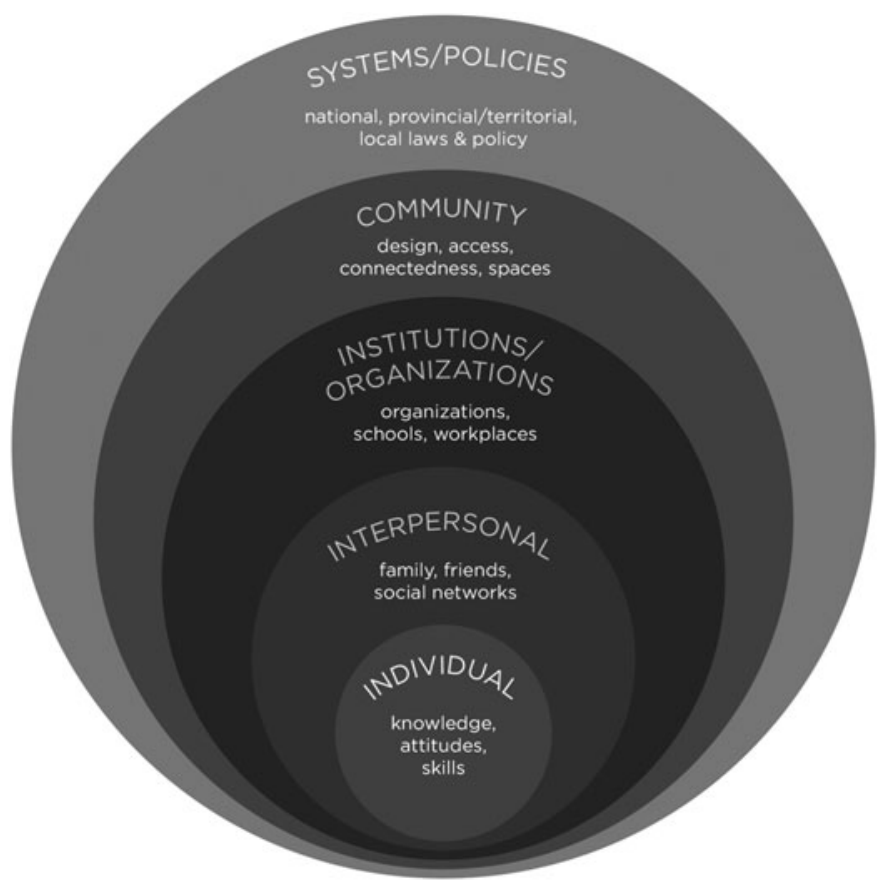

Figure 1. Social ecological model for preventing childhood obesity. ${ }^{9}$

children spend their time. The social ecological model (SEM) in Figure 1 illustrates how obesity prevention initiatives have been integrated across multiple levels. ${ }^{7-9}$ The model illustrates the potential impact at the community and organizational levels through local programs and policies as well as federal and state policies such as the Child Nutrition Reauthorization Act. ${ }^{10}$

A major objective of this study is to identify and describe the obesity prevention efforts implemented across settings in the four communities that may have contributed to the reported declines. In this supplement, Jernigan et al. describe how various inputs from critical components of these efforts may have interacted across levels to impact children's weight status. Dooyema et al. review enacted state policies that may have collectively reinforced the impact of the efforts.

\section{The Childhood Obesity Declines Project}

The goal of the Childhood Obesity Declines (COBD) project was to systematically explore factors that operate at multiple levels that may have contributed to declines in childhood obesity reported by the four communities included in this study: Anchorage, Alaska; Granville County, North Carolina; New York, New York; and Philadelphia, Pennsylvania. The study was exploratory and designed to understand the strategies that occurred in these municipalities, along with contextual factors that may have influenced or potentiated those strategies. The work was guided by members of the National Collaborative on Childhood Obesity Research (NCCOR), funded by the Robert Wood Johnson Foundation, and implemented by ICF (the COBD Team).

\section{Methods}

The COBD project was built on an approach called the Systematic Screening and Assessment (SSA) Method. ${ }^{11}$ The SSA Method was initially developed to identify promising initiatives being implemented in the field that were ready for rigorous evaluation to determine their appropriateness for broader replication. In this case, the SSA Method was adapted to verify obesity declines and identify strategies that influenced and supported the decline. See Kettel Khan et al. in this supplement for more details about the methods for this study.

\section{Study Components}

The COBD project included six primary components. The study team (1) scanned popular media reports as well as peer-reviewed literature to identify sites reporting declines in rates of childhood obesity in the United States; (2) selected sites for case studies based on established criteria; (3) reviewed site-provided and published documents to identify potentially relevant site-specific strategies; (4) identified key stakeholders at each location and administered an inventory of standardized questions to identify whether various obesity prevention strategies took place during the examined timeframe [strategies recommended by groups such as the Centers for Disease Control and Prevention (CDC) and the Health and Medicine Division of the National Academy of Medicine (formerly Institute of Medicine)]; (5) examined policy and contextual data for each site; and (6) conducted site visits to interview respondents knowledgeable about the strategies across multiple settings. This study focuses on results from the last/sixth phase - site visit interviews about strategies implemented in sites with documented significant obesity declines.

\section{Site Selection}

COBD began in 2014. Members of NCCOR provided an initial list of sites reporting COBD. In addition, popular media reports and published literature were scanned from 2010 to 2014, identifying a total of 19 US sites with reported declines in rates of childhood obesity. Criteria to select sites included children's height and weight measured objectively by trained staff; a minimum of two Body Mass Index (BMI) data collection periods, including baseline BMI no more than 10 years before the start of the COBD (2004) and follow-up BMI data no more than 5 years before the start of COBD (2009); a minimum of 2 years between BMI measurements; and a statistically significant decrease in rates of childhood obesity verified by the COBD team members. Ultimately, four sites met the selection criteria.

\section{Site Visit Interviews}

The COBD team used a snowball sampling method ${ }^{12}$ to identify key informants for interviews in each site across four settings: (1) community, (2) school, (3) early care and 


\begin{tabular}{l|c|c|c|c|c|}
\hline Table I. Number and Type of Interviewees by Site \\
\begin{tabular}{|l|c|c|c|c|} 
Strategy \\
Sevelopers
\end{tabular} & $\begin{array}{c}\text { Strategy } \\
\text { implementers }\end{array}$ & $\begin{array}{c}\text { Partners/Community } \\
\text { members }\end{array}$ & $\begin{array}{c}\text { Evaluators/Researchers } \\
\text { Totals }\end{array}$ \\
\hline Anchorage, AK & 15 & 4 & 2 & 2 & 22 \\
\hline Granville County, NC & 7 & 4 & 3 & 9 & 16 \\
\hline New York City, NY & 4 & 9 & 8 & 3 & 30 \\
\hline Philadelphia, PA & 7 & 5 & 8 & 15 & 23 \\
\hline Totals & 33 & 22 & 21 & & 91 \\
\hline
\end{tabular}

education (ECE), and (4) healthcare. Beginning with the authors of published reports of the declines, informants were broadened to include those referred to the COBD team as knowledgeable about potentially relevant strategies occurring during or before the period of the declines. In each site, the COBD team identified 16 to 30 interviewees and collected site-specific information via weeklong site visits. In general, two COBD team members interviewed each respondent.

Respondents fell into four categories: (1) developers, who played a role in planning or developing major policies or programs in the sites; (2) implementers, who were directly responsible for the implementation of strategies; (3) partners and community members, who were representatives of community organizations engaged in promoting, supporting, or funding the strategies; and (4) evaluators and researchers, who played a role in evaluating one or more of the implemented strategies. Table 1 outlines the number of interviews conducted during each site visit and the types of respondents.

\section{Data Verification}

The COBD study team closely examined methods and data for 11 of the 19 initially identified sites - those found to pass all other exclusion criteria. All sites reported declines in children's height and weight and BMI based on objectively measured data. For these 11 sites, COBD study team members confirmed the validity of methods used for significance testing. In cases where significance testing had not been conducted, COBD study team members requested additional analysis by sites or independently analyzed data (for sites without capacity to do so) using two sample tests of proportions. This additional analysis indicated that declines in six sites were not statistically significant. (Despite confirmation of a statistically significant decline by the COBD study team, one of the five remaining sites was not selected based on its involvement in another ongoing study.) This process ultimately resulted in selection of four sites for this study.

In three of the four selected sites, the data were obtained from public schools, where nurses or trained school staff collected the measurements. In Granville County, data were obtained from Women, Infants, and Children (WIC) clinics, public health-sponsored child health clinics, and some school-based health centers. ${ }^{13}$ Across sites, the data underwent quality control, and researchers excluded biologically implausible measurements. Specifically, New York City and Anchorage used standards as defined by CDC BMI percentile for age and sex criteria. ${ }^{12}$ Philadelphia expanded the CDC standards with a Biologically Implausible Value (BIV) filter that excluded the following: height $<0.2$ or $>3.0 \mathrm{~m}$ or weights $<0.5$ or $>300 \mathrm{~kg}$. Granville excluded children aged $>2$ years whose BMI-for-age z-score $<-4.0$ or $z$-score $>5.0$. Table 2 presents results of significance testing for each site.

Site visit interviews were recorded and transcribed, and transcripts were entered into the Atlas.ti qualitative analysis program. ${ }^{14}$ The COBD team members developed

\section{Table 2. Reported Statistically Significant Obesity Declines in Study Sites}

\begin{tabular}{|c|c|c|c|}
\hline Site & Age or grade & Reported decline & Period of decline \\
\hline Anchorage, $\mathrm{AK}^{17}$ & $\begin{array}{l}\text { Students in grades } \mathrm{K} \text {, } \\
\mathrm{I} \text {, and } 3\end{array}$ & $\begin{array}{l}\text { Obesity declined from } 18.0 \% \text { to } 17.6 \% \text {, representing } \\
\text { a relative decrease of } 2.2 \%(p<0.001)\end{array}$ & $\begin{array}{l}2003-2004 \text { to } 2010-2011 \\
\text { school years }\end{array}$ \\
\hline Granville County, $\mathrm{NC}^{13}$ & Children $2-4$ years of age & $\begin{array}{l}\text { Overweight/obesity declined from } 36 \% \text { to } 29.7 \% \text {, } \\
\text { representing a relative decline of } 17.5 \%(p<0.01)\end{array}$ & 2005 to 2010 \\
\hline New York City, NY17 & Students in grades K-8 & $\begin{array}{l}\text { Obesity declined from } 21.9 \% \text { to } 20.7 \% \text {, representing } \\
\text { a relative decline of } 5.5 \%(p<0.001)\end{array}$ & $\begin{array}{l}2006-2007 \text { to } 2010-2011 \\
\text { school years }\end{array}$ \\
\hline Philadelphia, $\mathrm{PA}^{18,19}$ & Students in grades $\mathrm{K}-8$ & $\begin{array}{l}\text { Obesity declined from } 21.5 \% \text { to } 20.5 \% \text {, representing } \\
\text { a } 4.7 \% \text { relative decrease }(7.7 \% \text { for severe obesity }) \\
(p<0.001)\end{array}$ & $\begin{array}{l}2006-2007 \text { to } 2009-2010 \\
\text { school years }\end{array}$ \\
\hline
\end{tabular}




\begin{tabular}{|c|c|c|c|c|}
\hline Race/Ethnicity & $\begin{array}{l}\text { New York, } \\
\text { New York } \\
\text { (2011) (\%) }\end{array}$ & $\begin{array}{c}\text { Philadelphia, } \\
\text { Pennsylvania } \\
\text { (2010) (\%) }\end{array}$ & $\begin{array}{l}\text { Granville County, } \\
\text { North Carolina } \\
\text { (2012) (\%) }\end{array}$ & $\begin{array}{c}\text { Anchorage, } \\
\text { Alaskad } \\
(2011)(\%)\end{array}$ \\
\hline White & 44.3 & 41.4 & 60.6 & 67.3 \\
\hline Black & 25.2 & 44.0 & 32.6 & 5.5 \\
\hline Hispanic/Latino (all races) & 28.4 & 11.6 & 7.5 & 7.5 \\
\hline Asian & 12.7 & 6.2 & 0.6 & 7.7 \\
\hline American Indian/Alaska Native & 0.4 & 0.3 & 0.4 & 6.5 \\
\hline Native Hawaiian/Other Pacific Islander & 0.1 & 0.0 & 0.0 & 1.9 \\
\hline
\end{tabular}

Percent shown is the racial and ethnic breakdown of the overall population in each location for the Childhood Obesity Declines study follow-up period (shown in parenthesis).

Source:

aU.S. Census Bureau (2007-20II). American Community Survey (New York, NY). Available at https://factfinder.census.gov/faces/tableservices/ jsf/pages/productview.xhtml?src=bkmk Last accessed September 28, 2017.

bU.S. Census Bureau (2006-2010). American Community Survey (Philadelphia, PA). Available at https://factfinder.census.gov/faces/tableservices/jsf/ pages/productview.xhtml?src=bkmk Last accessed September 28, 2017.

¿U.S. Census Bureau (2008-20I2). American Community Survey (Granville County, NC). Available at https://factfinder.census.gov/faces/ tableservices/jsf/pages/productview.xhtml?src=bkmk Last accessed September 28, 2017.

dU.S. Census Bureau (2007-20II). American Community Survey (Anchorage, AK). Available at https://factfinder.census.gov/faces/tableservices/ jsf/pages/productview.xhtml?src=bkmk Last accessed September 28, 2017.

a codebook to reflect the primary areas of the interview guides. These codes helped to identify, for example, common strategies across interviewees and barriers or facilitators of the strategies.

\section{Results}

\section{Description of Site Contexts}

The four sites in this study varied in geography and in size of the population and school districts. Granville County is primarily rural and has a population of about 60,000, whereas Anchorage is primarily urban, but has a small percentage of rural environs, and a population of about 300,000 people. New York City and Philadelphia are urban cities with populations of $\sim 8.3$ and 1.6 million, respectively (Table 3 for the racial/ethnic diversity of each site). New York City and Philadelphia have the largest and eighth-largest school districts in the nation (about 1.1 million students and about 190,000 students, respectively $)^{15}$; Anchorage has $\sim 48,500$ students, and Granville County has 8100 students.

\section{The Nature of the Reported Declines}

Table 2 provides a synopsis of the obesity declines verified for each site. The data represent cohorts of children across the study period. Subgroup differences were identified for many sites. Significant declines in rates of age-specific obesity were found primarily in elementary and middle school children in three sites, and in preschool children in Granville. While sites collected data on all ages of children (with exception of Anchorage where student weight status was collected in grades $\mathrm{K}, 1,3,5$, and 7), significant declines were found in some subpopulations.

In Anchorage, declines in obesity were significant for only younger children (grades K, 1, and 3), boys, white students, and children in schools where $50 \%$ or less of students were receiving subsidized lunches. ${ }^{16}$ In New York City, obesity decreased significantly among children ages 5-14 (grades K-8) and for racial/ethnic subpopulations; however, the decrease was smaller among African American $(1.9 \%)$ and Hispanic $(3.4 \%)$ children than among Asian/Pacific Islander (7.6\%) and white (12.5\%) children. ${ }^{17}$ In Philadelphia, overall declines were reported for students in grades K-8. Subgroup analysis revealed that declines in obesity (and severe obesity) were significant for Hispanic girls, African American, non-Hispanic white, and Asian (obesity only) boys. ${ }^{17}$ A later study in Philadelphia found similar significant declines in rates of obesity for the same racial/ethnic groups, but declines were attenuated for girls, and specifically Hispanic girls. ${ }^{18}$

Subgroup differences were not examined in Granville County as that information was not made available at the county level. Overall, declines were evident among racial/ ethnic children in New York City and Philadelphia, although the decrease was smaller in New York City. In all sites, strategies were implemented to target entire populations. However, some strategies were aimed at diverse populations at higher risk for obesity, including low- 
income groups. Examples included providing nutritious foods at schools qualifying for free/reduced-price meals to families receiving Supplemental Nutrition Assistance Program (SNAP) benefits and at corner stores in low-income neighborhoods.

\section{Implemented Strategies}

Sites reported at total of 121 different implemented strategies. From these, site visitors identified a subset in each site that were described as having broad reach among the population of children who experienced the declines. These strategies were implemented primarily in schools and early childhood settings. The COBD team termed these "targeted strategies." Figure 2 presents a combined timeline showing the targeted strategies for each site during the period of the decline. (In Philadelphia, two targeted strategies occurred before the study period). Nontargeted strategies occurring before and immediately following the decline period also are shown. The nontargeted strategies were implemented primarily in the community and healthcare settings and may have amplified other efforts, thus "enabling" the strategies directed at children.

Many of these strategies (targeted and nontargeted) were a mix of programs, policies, and media campaigns designed to improve healthy food access and reduce less nutritious foods; increase physical activity; and create health-promoting built environments. Programs bring together key elements that focus on changing behaviors and environments that are conducive to healthy lifestyles; policies can help to codify desired changes; and media campaigns bring awareness to these issues.

Site visitors identified targeted strategies by considering each strategy's breadth and directness of reach to the population that experienced declines (e.g., districtwide policies impacting school children). From this process, we identified 13 targeted strategies (3 in Anchorage, 3 in Granville, 3 in New York City, and 4 in Philadelphia). These targeted strategies are identified and organized by setting, focus area, and type in Table 4 . Of the 13 targeted strategies, 9 occurred in schools and 5 in ECE settings; 7 focused on nutrition, 3 on physical activity, and 3 addressed both nutrition and physical activity; 7 had policy components, 2 had programmatic components, and 4 had both programmatic and policy components.

\section{What Targeted Nutrition-Related Strategies Occurred in Study Sites?}

Of the 10 targeted strategies with nutrition focus, 7 took place in only schools, 1 occurred in only the ECE setting, 1 took place in only the healthcare setting, and 1 occurred in multiple settings (i.e., the implementation of nutrition standards by city agencies occurred across multiple settings in New York City). These strategies had three main foci: (1) implementing districtwide nutrition standards; (2) using comprehensive school wellness policies; and (3) creating and executing nutrition education programs.
Changes in nutrition standards in public schools. All four sites implemented districtwide changes in school nutrition standards. Examples included the following:

- Meal standards

- Increasing servings of fresh fruits and vegetables

$\circ$ Eliminating whole and flavored milk and offering only skim or $1 \%$ milk

- Limiting sodium and cholesterol in school meals

- Promoting whole grains and low-fat or fat-free dairy and other products

- Establishing standards for competitive foods and prohibiting sugary drinks from school vending machines.

Changes in nutrition standards in ECE settings. Similar changes in nutrition standards also were evident in the ECE setting. As an example, the North Carolina Child Care Commission created licensing requirements for child care centers, including the following:

- Prohibited the serving of sweetened beverages, other than $100 \%$ fruit juice, to children of any age.

- Prohibited the serving of more than six ounces of juice per day to children of any age.

- Prohibited the serving of juice from a bottle.

- Prohibited the serving of whole milk to children 2 years of age or older.

- Prohibited the serving of flavored milk to children of any age.

- Created an exception from the rules for parents of children who have medical needs, special diets, or food allergies.

- Limited the number of grains containing added sugars and increase the number of whole grains.

- Limited foods high in fat content and salt.

Comprehensive school wellness policies-nutrition. Two of the four sites adopted comprehensive school wellness policies that included nutrition guidelines for school meals and snacks and drinks from vending machines, and classroom nutrition education. In Philadelphia, the districtwide school wellness policy established coordinated school wellness councils, and it set standards for all foods available on school property during the school day. For example, the standards limited snacks' total fat content to $7 \mathrm{~g}$ or less per serving and sodium content to less than or equal to $360 \mathrm{mg}$ per day; they offered only skim and $1 \%$ milk; and they banned the sale of candy during the school day. The wellness policy also required nutrition education that promoted fruit, vegetables, whole-grain products, low-fat and fat-free dairy products, healthy food preparation methods, health-enhancing nutrition practices, and caloric balance between food intake and energy expenditure.

Through executive order, New York City adopted comprehensive nutrition standards for all foods purchased and served by city agencies and their programs, including public schools and ECE centers, requiring agencies to comply with science-based standards for calorie, sugar, sodium, and fiber content for all meals and snacks purchased or prepared in city-funded programs. 

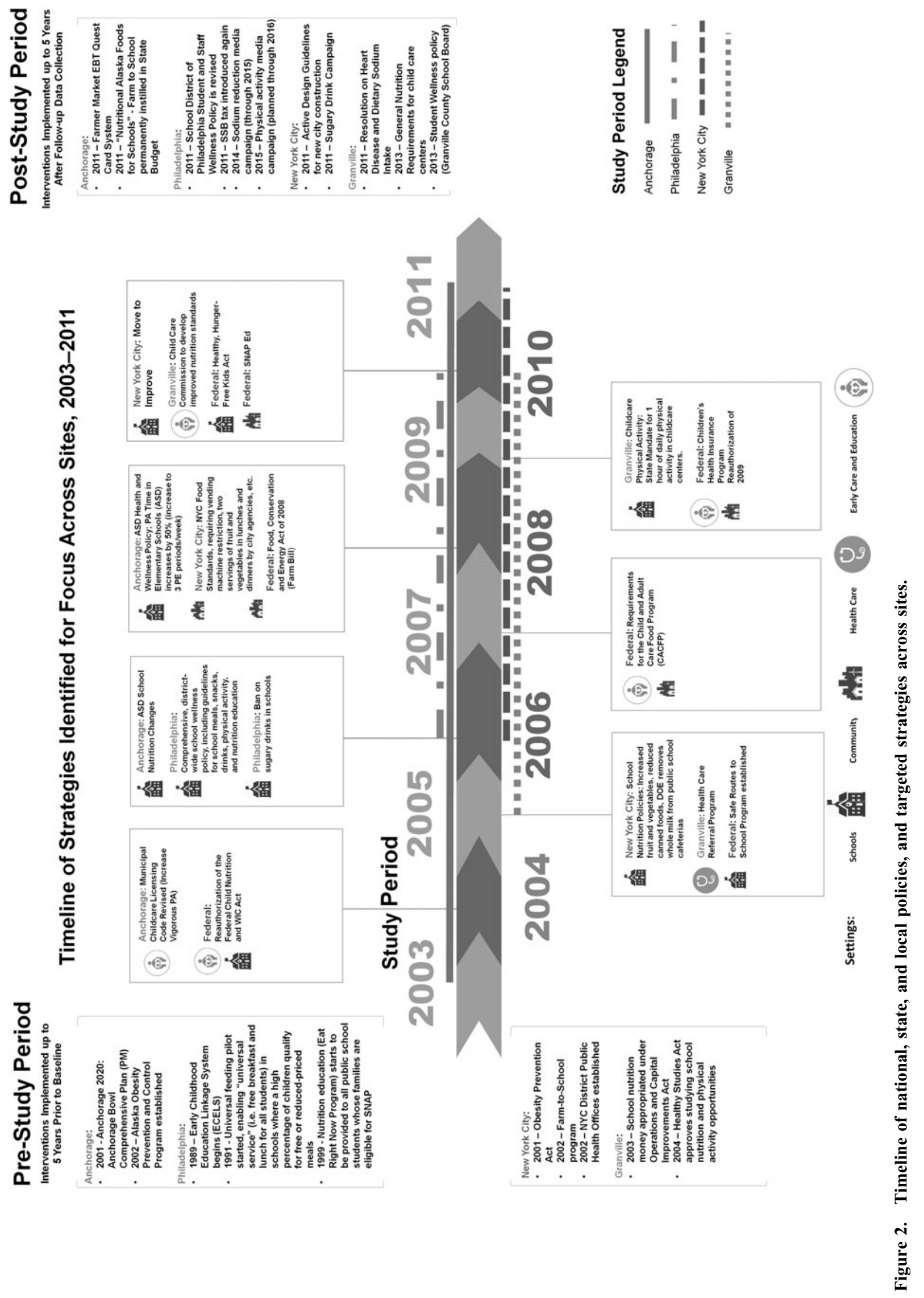


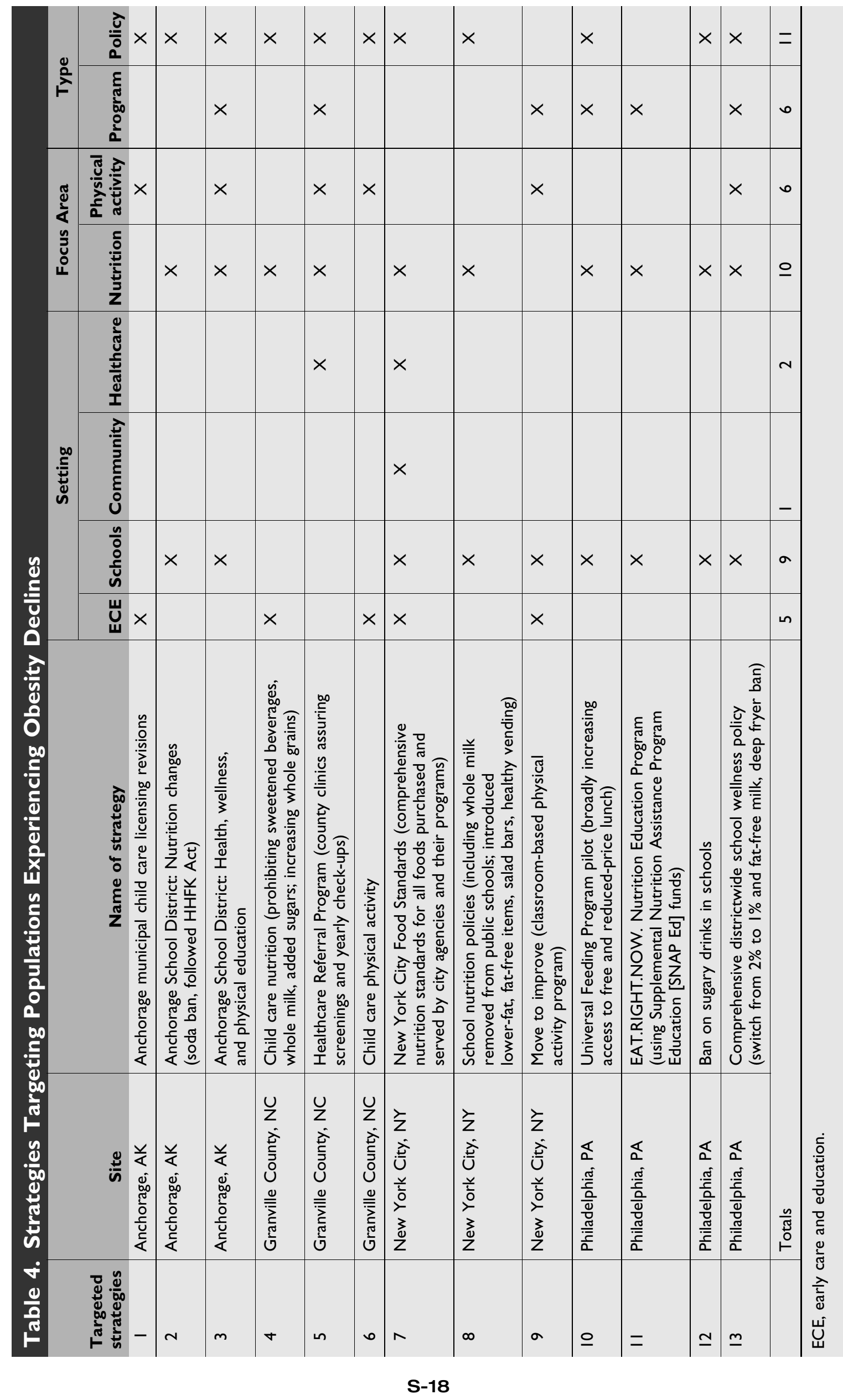


Nutrition education. Almost all sites implemented nutrition education as a targeted strategy designed to raise awareness and teach children and parents/caregivers about healthful behaviors. In Granville, the Community Care Network clinics (healthcare setting) implemented a Health Check program that incorporated BMI screenings with education to providers and parents about childhood obesity. This expanded to include family referrals to nutrition education, including a referral to a nutritionist for any child found to be at risk for overweight or obesity. The nutrition education offered to parents included demonstrations about the amount of sugar in soda, meal planning, grocery store tours, and strategies for purchasing healthy items on a limited budget.

In Philadelphia, the EAT.RIGHT.NOW Nutrition Education Program (in the school setting), supported through SNAP ED funding, was designed to reach students in schools with a majority of low-income populations eligible for free or reduced-price lunch. In Alaska, 22 health and wellness education teachers were hired and trained to implement the health curriculum in grades 4-6 and to become the experts in the building on health and wellness topics.

\section{What Targeted Physical Activity-Related Strategies Occurred in Study Sites?}

Six of the 13 targeted strategies across sites focused on physical activity. Of these, two occurred in school settings, two in the ECE setting, one in the healthcare setting, and one occurred in both the school and ECE settings. The physical activity strategies focused on (1) comprehensive school wellness policies with a physical activity component; (2) child care licensing requirements; and (3) public school classroom-based physical activity.

Comprehensive school wellness policies-physical activity. Two sites had comprehensive school wellness policies with a physical activity component. Philadelphia implemented a physical education (PE) curriculum, including a physical fitness assessment, for each student. The policy also included using a fitness assessment tool for grades 3 through 12, and PE components related to movement, cooperation, fair play, and social skills; at least $50 \%$ of PE class time was required to be spent in moderate-tovigorous physical activity. The policy did not, however, have a minute-based physical activity requirement. In the classroom, elementary students are given "movement breaks" for every 90 minutes of seat time, time is devoted in the elementary schedule for supervised and safe recess, and students are taught information and skills to understand the benefits of being physically active.

Alaska introduced a new health curriculum that taught nutrition and PE topics as well as others, and it was integrated with the PE curriculum that taught "lifelong" physical activity skills and values. Health, wellness, and PE time also were increased from 60 minutes per week of $\mathrm{PE}$ only to 90 minutes of PE and plus 30 minutes of health and wellness instruction per week in elementary schools.
Classroom-based physical activity. Two of the four sites used non-PE classroom-based activities to increase physical activity, integrating fitness breaks with the core academic curriculum. In New York City, the Move to Improve program was developed in partnership with the Department of Education and counted toward the 120 minutes of PE per week mandated by the state. The program trained school teachers and directors to implement the specific curriculum and incorporate physical activity in the classroom. Students participated in moderate physical activity for 8 to 12 weeks with five program goals ranging from 30 minutes per day for 4 days to 60 minutes per day for 7 days. As mentioned earlier, Philadelphia trained teachers and provided elementary students with "movement breaks" for every 90 minutes of seat time.

ECE physical activity licensing requirements. Two of the four sites implemented child care licensing requirements that increased physical activity for young children in the ECE setting. The State of North Carolina mandated 1 hour of play per day for all child care centers. Centers in Granville implemented the requirement by including instructor-led time for the first 30 minutes and free play for the last 30 minutes. The requirement was enforced by center directors or principals for the pre-K setting, and teachers were required to build the hour into their schedules. Also, the Municipality of Anchorage revised its child care licensing code to increase the rigor of requirements for physical activity. Children in fullday child care center programs were required to be provided with opportunities for "a minimum of 20 minutes of vigorous physical activity indoor or outdoor, for every 3 hours the facility is open."

Physical activity health education. One of the four sites offered health education in the healthcare setting to parents, reminding them to reduce sedentary behaviors and increase moderate-to-vigorous physical activity per day for their children. Through the Healthcare Referral Program from the Granville-Vance Health Department, providers and case managers gave "prescriptions" to parents reminding them that children should have 2 hours or less of TV or video games, and 1 hour or more of moderate-tovigorous activity per day.

\section{Facilitators of Nutrition and Physical Activity-Targeted Strategies}

Many of the nutrition strategies were enhanced by federal guidelines and policies such as the 2007 federal requirements for the Child and Adult Care Food Act, the reauthorization of the Federal Child Nutrition and Women, Infants and Children (WIC) Act in 2004, and Healthy, Hunger-Free Kids Act. ${ }^{19}$ In most sites, these federal guidelines reinforced what was already occurring by increasing nutritional standards across multiple settings. They also were often informed by recommendations of the Health and Medicine Division of the National Academy of Medicine. ${ }^{20}$ These guidelines as well as state policies that created licensing requirements (e.g., as described above in North Carolina and noted in Dooyema 
et al. in this supplement) and citywide policies that facilitated districtwide changes (e.g., as described above in New York City) contributed to the changes in nutrition across these sites.

In all sites, the physical activity requirements could not be implemented without endorsement and participation from teachers and school administrators. Across strategies, state or city officials (e.g., governors, mayors) as well as leaders in the departments of health (e.g., directors, program managers) and education (e.g., superintendents, principals) were reported as instrumental and served as champions in supporting these efforts. In addition, partnerships across multiple sectors as reported by all sites (e.g., education, health, community, and faith-based organizations) led to promoting healthy lifestyles and environments. The strategies implemented across various sectors, settings, and levels were described by some respondents as a "layering effect" which, according to those respondents, improved the chances for reducing obesity rates.

\section{Addressing Health Disparities}

Many of the targeted strategies were implemented broadly, and it is likely that child populations experiencing health disparities were exposed to many of the targeted strategies. In addition, some targeted strategies directly addressed children from health disparate populations. One example was the Universal Feeding Pilot in Philadelphia. This program provided free nutritious breakfast to all students in qualifying schools (i.e., those eligible for free and reduced-price meals), and reached about 200 eligible public schools $(\sim 80,000$ children). The EAT.RIGHT.NOW nutrition education program also was provided to students in these schools. Another example is the Healthcare Referral Program in Granville, which was designed to reach primarily lowincome populations and children receiving Medicaid.

Across sites, $\sim 14$ nontargeted strategies were concentrated in neighborhoods and among populations with the greatest need. Although aimed at health disparate populations, the reach was limited (i.e., only in small pockets within a neighborhood), or the primary focus was not children. Some of these strategies enabled healthful behaviors to be an option for low-income children and their families through exposure in the neighborhood. Examples include the Healthy Corner Store Initiative and Philly Food Bucks in Philadelphia and Health Bucks in New York City, all of which reached those using SNAP benefits. These strategies had the goals of increasing availability and affordability of healthy foods among low-income populations. In Anchorage, many children may have been reached through the customary, mandated physical activity and nutrition-based programs and curricula implemented in the majority of Head Start centers, where low-income children are the predominant enrollees.

\section{Conclusion}

There are some limitations to the study to consider. This study was exploratory. While many of the identified strategies temporally preceded the COBD in the four sites, we were not able to explore causality. In addition, a limited project timeframe allowed for only a small subset of individuals to be interviewed. Finally, a great deal of the information collected was retrospective and based on recall. When possible, the study team used documented reports to determine the details and timing of policy changes and strategy implementation.

Despite differences in site context (e.g., size and geography, settings of implementation and combination of components), targeted strategies that appeared to facilitate COBD shared commonalities. In particular, high-level stakeholders and champions were invested in and promoted the efforts. In all sites, active support of strategies was reported from state or city officials such as governors and mayors, as well as education sector leaders such as superintendents and principals, and health sector leaders, including city and state health department directors. Furthermore, all sites reported cross-sector partnerships. This was noted among public agencies such as departments of health and education. It was also noted among nongovernmental community organizations such as those that were faith-based, promoted maternal and child health, and targeted improving the food environment.

Nutrition strategies in particular were often implemented preceding federal policies such as the Healthy, Hunger-Free Kids Act. ${ }^{21}$ This allowed implemented strategies to be reinforced by federal policies. Also, related to national policies and programs, a number of the specific strategies used (such as reducing access to less nutritious foods, increasing access to more nutritious foods, or establishing required minutes in physical activity policy) reflect many of the recommendations of national groups such as the Health and Medicine Division of the National Academy of Medicine and the CDC. ${ }^{22}$

Strategies were described as occurring within multiple settings and at multiple levels, creating what some informants described as a "layering effect." Strategies were reported at the child level, the community level, the state level, and the federal level. The 13 targeted strategies primarily were implemented in the ECE setting and in the elementary school setting-by definition, environments directly reaching younger children. In addition, other, nontargeted strategies that respondents reported during the period of noted declines occurred in healthcare and community settings, and appeared to further magnify public health messaging. These "enabling strategies" could be hypothesized to amplify and reinforce the impact of the efforts that more directly targeted children.

Going forward, these findings underscore the importance of testing a hypothesized synergy of strategies. Informants described the efficacy of strategies across levels that map onto the SEM. ${ }^{9}$ In all sites, programs and policies were implemented across settings and within the context of supportive federal policies and initiatives. Particularly within communities, respondents described that the layering of multiple strategies across settings and levels made it 
difficult for people to "miss the messages" about improving nutrition and physical activity.

In summary, the importance of simultaneous public health messaging and multilayered initiatives, supported by cross-sector partnerships and active, high-level champions were identified as likely important contributors to success in attaining declines in prevalence of childhood obesity.

\section{Acknowledgments}

Robert Wood Johnson Foundation, ID No. 71772Analyzing the Signs of Progress in Childhood Obesity, Route 1 and College Road East, Princeton, NJ 08543-2316

\section{Author Disclosure Statement}

The authors did not report any conflicts of interest or financial disclosures. The findings and conclusions of this report are those of the authors and do not represent the official position of the Centers for Disease Control and Prevention, ICF, the National Institutes of Health, Robert Wood Johnson Foundation, or the US Department of Agriculture.

\section{References}

1. Ogden CL, Carroll MD, Lawman HG, et al. Trends in obesity prevalence among children and adolescents in the United States, 1988-1994 through 2013-2014. JAMA 2016;315:2292-2299.

2. Pan L, Freedman DS, Sharma AJ, et al. Trends in obesity among participants aged 2-4 years in the Special Supplemental Nutrition Program for Women, Infants, and Children - United States, 20002014. MMWR Morb Mortal Wkly Rep 2016;65:1256-1260.

3. Ogden CL, Carroll MD, Kit BK, et al. Prevalence of childhood and adult obesity in the United States, 2011-2012. JAMA 2014;311: 806-814.

4. Dietz WH, Economos CD. Progress in the control of childhood obesity. Pediatrics 2015;135; e559-e561.

5. Swinburn B. Obesity prevention in children and adolescents. Child Adolesc Psychiatr Clin N Am 2009;18:209-223.

6. Story M, Kaphings KM, Robinson-O'Brien R, et al. Creating healthy food and eating environments: Policy and environmental approaches. Ann Rev Pub Health 2008;29:253-272.

7. Institute of Medicine. Committee on Prevention of Obesity in Children and Youth. In: Koplan J, Liverman CT, Kraak VI (eds), Preventing Childhood Obesity: Health in the Balance. Washington, DC: The National Academies Press, 2005.

8. The Johns Hopkins Center for a Livable Future. Perspectives on Childhood Obesity Prevention: Recommendations from Public Health Research and Practice. 2007. Available at www.jhsph.edu/ research/centers-and-institutes/johns-hopkins-center-for-a-livablefuture/_pdf/research/clf_reports/childhoodobesity.pdf (last accessed February 16, 2018).
9. McLeroy K, Bibeau D, Steckler A, et al. An ecologic perspective on health promotion programs. Health Educ $Q$ 1988;15: 351-377.

10. Civic Impulse. S. 2507-108th Congress. Child Nutrition and WIC Authorization Act of 2004. Available at https://www.govtrack.us/ congress/bills/108/s2507 (last accessed February 16, 2018).

11. Dawkins N, Wethington H, Kettel Khan L, et al. Applying the systematic screening and assessment method to childhood obesity prevention. New Dir Eval 2010;33-49.

12. Centers for Disease Control and Prevention. Cut-offs to define outliers in the $2000 \mathrm{CDC}$ growth charts. Available at www .cdc.gov/nccdphp/dnpa/growthcharts/resources/biv-cutoffs.pdf (last accessed July 29, 2016).

13. Granville-Vance District Health Department. Priority-Chronic Disease and Lifestyle Issues. 2012 State of the County Health Report. Oxford, NC: Granville-Vance District Health Department, 2012.

14. ATLAS.ti. Version 7.5. Berlin: Scientific Software Development, 1999.

15. Snyder TD, and Dillow SA. Digest of Education Statistics 2013 (NCES 2015-011). National Center for Education Statistics, Institute of Education Sciences, U.S. Department of Education, Washington, DC.

16. Centers for Disease Control and Prevention. Obesity in K-7 students-Anchorage, Alaska, 2003-04 to 2010-11 school years. MMWR Morb Mortal Wkly Rep 2013;62:426-430.

17. Centers for Disease Control and Prevention. Obesity in K-8 students - New York City, 2006-07 to 2010-11 school years. MMWR Morb Mortal Wkly Rep 2011;60:1673-1678.

18. Robbins JM, Mallya G, Polansky M, et al. Prevalence, disparities, and trends in obesity and severe obesity among students in the Philadelphia, Pennsylvania, school district, 2006-2010. Prev Chronic Dis 2012;9:120118.

19. Robbins JM, Mallya G, Wagner A, et al. Prevalence, disparities, and trends in obesity and severe obesity among students in the School District of Philadelphia, Pennsylvania, 2006-2013. Prev Chronic Dis 2015;12:150185.

20. Civic Impulse. S. 3307-111th Congress. Health Hunger-Free Kids Act of 2010. Available at https://www.govtrack.us/congress/bills/ 111/s3307 (last accessed February 16, 2018).

21. Institute of Medicine. Accelerating Progress in Obesity Prevention: Solving the Weight of the Nation. Washington, DC: The National Academies Press, 2012.

22. Centers for Disease Control and Prevention, Division of Nutrition, Physical Activity and Obesity Nutrition. Physical Activity and Obesity Prevention Strategies. Available at www.cdc.gov/obesity/ resources/strategies-guidelines.html (last accessed February 16, 2018).

Address correspondence to: Phyllis G. Ottley, PhD Division of Violence Prevention Centers for Disease Control and Prevention 4770 Buford Highway Atlanta, GA 30341

E-mail:pottley@cdc.gov 